\title{
Notes per a una hipòtesi d'atribució de «E tot qan m'a ofes en aiqest an» (BdT 461.80) Cecilia Cantalupi
}

\section{Les notícies sobre Guilhem Figueira als manuscrits}

A vuit segles de la vida de Guilhem Figueira, la tradició manuscrita ens fa arribar el nom del trobador tolosà de diverses maneres. Per començar, apareix esmentat a les rúbriques atributives dels seus poemes, amb l'afegit de la vida copiada als cançoners B, K i l. En forma d'autonominatio i en posició destacada per la rima, també en reporta el nom el seu poema «Un nou sirventes ai en cor que trameta» (BdT 217.8, v. 53), copiat als cançoners llenguadocians $C$ i $R,{ }^{2}$ així com la invocació inicial d'una tenso amb el seu paisà Aimeric de Peguilhan («N'Aimeric qe·us par del pro Bertram d'Aurel»», BdT 217.4C 10.9, Vv. 6 i 13). L'única referència fora del corpus trobadoresc la trobem en una declaració davant la Inquisició de Tolosa de 1274 (Biller, Bruschi \& Sneddon 2011: 578-591), que ha perviscut gràcies a la còpia de fons d'arxiu del Midi finançada per Jean-Baptiste Colbert.3 L'interrogat hi afirma que havia escoltat «quandam cantilenam sive coplas pluries, quas fecit [...] qui-

1 Es tracta dels manuscrits següents: Paris, Bibliothèque nationale de France, fr. 1592, fr. 12473 i fr. 854 .

2 Paris, Bibliothèque nationale de France, fr. $856 \mathrm{i}$ fr. 22543.

3 Ara consultable a 'Languedoc - Doat' de la BnF, vol. XXV, ff. 198v-199r. Vegeu Boffito (1897), Omont (1916), Léglu (2002), Albaret (2003) i Bruschi (2003). dam ioculator qui vocabatur Figuera» ('alguna cantilena o diverses cobles que va fer un joglar que es deia Figuera') i recita de memòria alguns versos del seu sirventès contra Roma («D'un sirventes far», BdT 217.2).

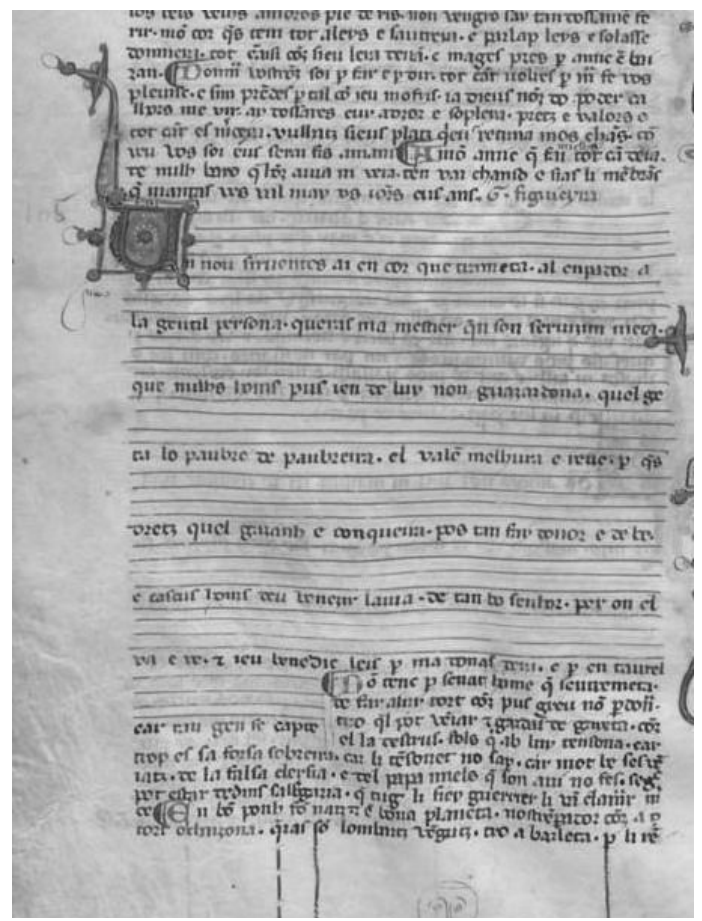

Detall de l'inici del sirventès de Figueira al cançoner trobadoresc $R$ (París, BnF, fr 22543, f. 95rb). 
Com evidencia l'esment en un document inquisitorial, es tracta d'un trobador amb una recepció possiblement penalitzada pel contingut marcadament ideològic de bona part dels seus poemes. Per això és molt rellevant la possibilitat de reconèixer el seu nom, sigui el de fonts o el patronímic, a les citacions en tres poemes coetanis transmesos només pel cançoner $H^{4}{ }^{4}$ En aquestes circumstàncies les citacions queden revestides d'un cert pes documental - que cal prendre, però, amb cautela-, a l'hora de definir una figura difícil de concretar històricament, ja que ens permeten, a grans trets, dibuixar les relacions de Figueira amb altres poetes, d'origen autòcton o bé faidits, que devia haver conegut a Itàlia.

Se l'ha identificat com el «Figera'l d [e]ptor» de la cobla d'Aimeric de Peguilhan «Bertram d'Aurel, s'aucizia» (BdT 10.13, v. 2). Aimeric hi respon a la insolent estrofa «Bertram d'Aurel, si moria» (BdT 217.1b), en què Guilhem Figueira l'havia titllat com a vell, avariciós i oportunista. Juntament amb les dues altres rèpliques que segueixen, de Bertran d'Aurel (BdT 79.1) i Lambert (BdT 280.1), configuren una collecció de coblas que serà la font parafrasejada a la vida de Guilhem per immortalitzar-lo com a freqüentador assidu de tavernes, bordells i personatges de mala vida, verd d'enveja per l'èxit dels seus collegues més famosos i celebrats.

«Guillems Figuera si fo de Tolosa, fils d'un sartor, et el fo sartres. E quant li Franses aguen Tolosa, si s'en venc en Lombardia. E saup ben trobar e cantar; e fez se joglars entre los ciutadis. Non fo hom que saubes caber entre.ls baros ni entre la bona gen; mas mout se fez grazir als arlotz et als putans et als hostes et als taverniers. E s'el vezia bon home de cort venir lai on el estava, il n'era tristz e dolenz; et ades se penava de lui baissar e de levar los arlotz> (Boutière \& Schutz 1964: 434).

Un dels casos més discutits per la crítica és la possible identificació de Figueira amb el «Guilhem Gauta-segnada» evocat per Aimeric de Peguilhan a la cobla «Anc tan bella espazada» (BdT

4 Ciutat del Vaticà, Biblioteca Apostolica Vaticana, Vat. Lat. 3207.
10.9). És una altra rèplica sarcàstica a Figueira, en aquest cas a «Anc tan bel colp de joncada» (BdT 217.1a), segurament inspirant-se en l'esparsa de Paves «Anc de Roland ni del pro n'Auliver» (BdT 320.1). L'última citació apareix en una cobla esparsa de Sordello, copiada al cançoner $\mathrm{H}$ a poques pàgines de distància de les precedents. L'esment explícit del trobador mantuà a un «Fige[i]ra» a final del primer vers rememora un cop d'espasa amb què un tal «n'Auziers» (identificat amb el trobador Guilhem Augier Novella) va ferir Guilhem a la galta (Calzolari 1986: 43-45). La coincidència entre aquest incident i la «bella espazada» de què parla Peguilhan a «Anc tan bella espazada» i, indirectament, als vv. 11-12 de «Bertram d'Aurel, s'aucizia» no va passar per alt a Giovanni Maria Barbieri i, malgrat les reserves d'alguns estudiosos, la identificació es pot considerar acceptada. ${ }^{5}$

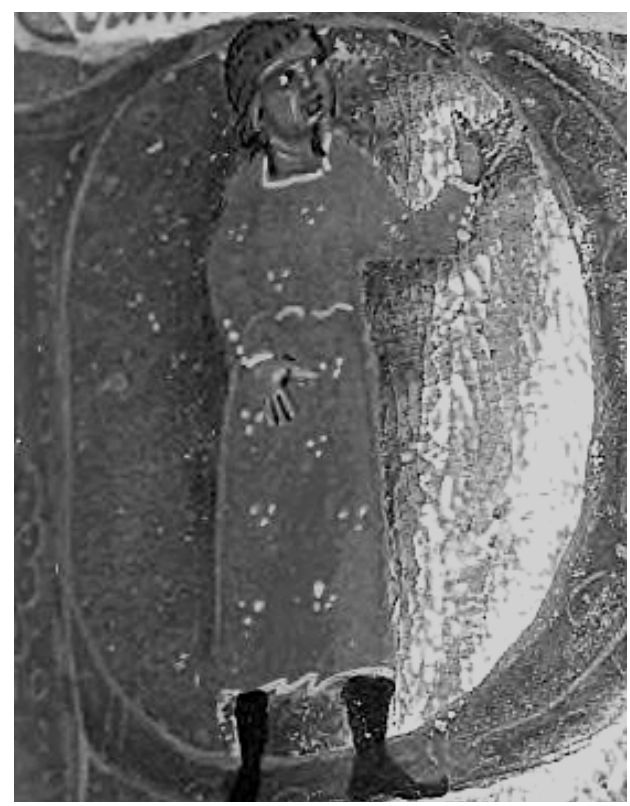

El trobador Guilhem Figueira al cançoner $K$ (París, BnF, fr. 12473, f. 95).

5 Vegeu un panorama de les diverses posicions a Boni (1954: XIX, n. 30), que per part seva es mostra cautelós. Barbieri afirma «Guilem Figera, che fu Dottore, scrittore di Serventesi, e maldicente, onde ne rilevò sul viso un fregio, come gli rimproverano Amerigo di Peguillan [...] et Sordello» (Tiraboschi 1790: 119-120). 


\section{El corpus de coblas d'escarni} als cançoners $H$ i $P$

Abans de plantejar alguns dels problemes interpretatius que presenten, vegem les edicions de referència de totes aquestes peces, afegint-hi tres textos sense rúbrica de to i formulacions similars, copiats al f. 55 r del cançoner occità $P$ i relacionats amb Aimeric de Peguilhan i Sordello, que aquí volem estudiar conjuntament. Es tracta del manuscrit Florència, Biblioteca Medicea Laurenziana, Plut. XLI.42. Vegeu el treball imprescindible de Noto (2003), on se cita la bibliografia precedent.

1. BdT 217.4C $10.36(H, f .50 v)$

I. N'Aimeric, qe·us par del pro Bertram d'Aurel? C'a Breissa joget l'autrer d'un joc novel e dis doas vez eschah ab un coltel a.N Guillelm del Dui-Fraire, qe volc l'eschah desfaire; mas Bertramz levet del joc can Guillelms cuidet traire.

II. Figera, Bertramz fetz be, car ses apel laise.l joc sobre.l maiestre d'En Sordel; qe can trop monton revit, non es ges bel; e.l seus contrajogaire fora tost revidaire.

Doncs fetz qe savis Bertramz, car ses dan s'en saup raire.

III. N'Aimeric, bos jogaire fon Bertramz l'envidaire; mas trop tost laisset l'envit qe Guillelms li volc faire.

IV. Figer', anc per lo fraire no fon del joc laissaire Bertramz, enans per desdeing qe tan pugnav'a traire. (Shepard \& Chambers 1950: 182-184)

2. BdT 217.1b 10.13 79.1 280.1 (H, f. 52 r)

I. (Guilhem Figueira)

Bertram d'Aurel, se moria

n'Aimerics anz de Martror, digatz a cui laissaria son aver e sa ricor c'a conques en Lombardia suffertan freit e langor? Ço.m dison gl'albergador.
Pero ben fez la Metgia, e dis del rei gran lauzor, sol q'el so tegn'ad honor.

II. (Aimeric de Peguilhan) Bertram d'Aurel, s'aucizia n'Auzers Figeral'। deptor, digatz a cui laissaria lo seu fals cor traidor, plen d'enjan e de bauzia e d'enoi e de folor, d'anta e de desonor? Ni putans qi menaria? Ni arlot ni bevedor qe farian de seignor?

III. (Bertran d'Aurel) N'Aimeric, laissar poria a.n Çoanet lo menor l'enjan e la tricharia, car el viu d'aital labor, e l'enoi e la folia a N'Auzer lo fegnedor, et a.N Bude.l desonor, et $a \cdot N$ Lambert la putia, e.l beure a.N Conplit-Flor, e.Is arlotz a N'Amador.

IV. (Lambert)

Seigner, scel qi la putia m'en laissa, s'en fai honor, qu'eu mo teing a manentia qi m'en fai prez ni largor, c'anc a nuill jorn de ma via no voill far autre labor, qe fotres miac tal sabor qu'eu ne laissei la clerzia e teng mon vet per prior e lo con per refreitor.

(Shepard \& Chambers 1950: 94-96) 


\section{BdT 320.1 (H, f. $52 r)$}

\section{(Paves)}

Anc de Roland ni del pro N'Auliver non fo auzitz us colps tan engoissos cum scels qe fez Capitanis l'autrier a Florença, a·N Guillem l'enojos; e no fos ges d'espada ni de lanza, anz fo d'un pan dur e sec sus en l'oill, q'estop'e sal et ou, aital mesclanza I'i mes hom destenprada ab orgoill. (Shepard \& Chambers 1950: 73)

\section{BdT 217.1a $10.9(H$, f. $52 r)$}

I. (Guilhem Figueira)

Anc tan bel colp de joncada

no cuit qe hom vis

com det l'autrer Jacopis

a·N Guillelm Testa-pelada;

qe, qi qe n'aia desport,

el aia ira e desconort,

e, setot ac de joncada.l cap blanc,

mantas vez l'a agut negre de sanc.

II. (Aimeric de Peguilhan)

Anc tan bella espazada

no cuit qe hom vis

com det N'Auzers sus el vis

a'n Guillelm Gauta-segnada,

q'el vis lo feri tant fort

c'un petit n'a l'un oill tort,

e.l cill qe sol aver negr'er a blanc

e. cais plus ros d'escerlatra e de sanc.

(Shepard \& Chambers 1950: 79-80)

\section{BdT 437.33 (H, f. 55V)}

(Sordello)

[S]i tot masaill de sirventes Fige[i]ra ab sa lenga falsa e menssongieira, sofrir lo'm taing, tal paor ai no'm feira ab l'espada ab qe.l feri n'Auziers, car no lli valc capiros ni viseira de la galta no.ll'en fezes cartiers; e pois n'ac patz ferma d'aital maineira, c'anc no $\cdot$ ill costet mezinar dos deniers (Boni 1954: 166-167)

6. BdT 10.7a 437.3a (P, f. 55 r)

I. (Aimeric de Peguilhan)

Anc al temps d'Artus ni d'ara

no crei qe homs vis

tan bel colp cum en las cris

pris Sordel[s] d'un'engrestara;

e se.l colps non fo de mort

sel qe.l penchenet n'ac tort;

mas el a.l cor tan umil e tan franc

q'el prend en patz toz colps pois no*i a sanc.

II. (Sordello)

Anc persona tan avara

no crei qe homs vis

cum a.I veils arlots meschis

n'Aimeric[s] ab trista cara.

Sel qe.l ve a pez de mort;

e se tot a son cors tort

e magr'e sec e vel e clop e ranc, mil aitans dis...q'el no fes anc.

(Boni 1954: 173-175)

\section{BdT $46 \mathbf{6 1 . 8 0}(P, f .55 r)$}

E tot qan m'a ofes en aiqest an de bon talan perdon a Ser Sordel, q'el meteis me venzara jugan, per qe nom cal ausir lo de coutel; q'el savei ben q'amdos sos palafres e son destrier el a jugat, totz tres; s'el ven a flum, e noill a gau ni pon, despoilla si e mostra son reon (De Bartholomaeis 1931: II, 73) 


\section{El retrat de la joglaria a les coblas d'escarni}

Dins de seccions específiques dels cançoners $H$ i $P$, tots dos de factura italiana, els copistes-compiladors han recollit les set coblas que acabem d'esmentar (vegeu el requadre de les pp. 9-10), pertanyents a un gènere líric que, de manera massa simple, sovint es considera menor a causa de la brevetat, d'una suposada manca d'originalitat formal i del repertori de temes usuals: moral, propaganda política, sàtira personal, humor, paròdia (Poe 2000a: 68). Tanmateix és un gènere que, sobretot en el vessant satíric, sembla molt apreciat pel públic italià del segle XIII, a jutjar per l'espai privilegiat que li reserven diversos manuscrits de lírica trobadoresca copiats en scriptoria italians. ${ }^{6}$

En aquest vessant satíric de la producció breu que ara ens interessa analitzar (intercanvis de coblas, tensons breus i coblas esparsas), els arguments que generen comicitat són molt variats, però destaquen els atacs ad hominem - en una sola composició o en forma d'atac i resposta, amb un esquema mètric i de rimes comú - en els quals es materialitzen jocs de creació poètica, potser improvisada. Els poetes discuteixen amb sarcasme sobre qüestions cèlebres, públiques o privades, centrades sobretot en els defectes físics i morals dels collegues, en general ben coneguts pel públic, i també en incidents ridículs i minúsculs en què s'ha vist involucrada la víctima de torn, que pot eventualment fer una rèplica poètica. Desafiaments similars, amb ofenses recíproques, degueren ser l'origen dels set textos esmentats. Expliquen fragments d'una història i d'uns costums, sempre en referència als mateixos joglars, dels quals es fa befa evocant de manera recurrent els mateixos defectes. El públic de la cort o de la taverna, segurament reduït, s'entretenia alhora que, de ben segur, es divertia, perquè intuïa en quin punt exacte seria atacada la víctima i sabia desxifrar les alllusions rimades, sovint molt agudes, amb un tipus d'humor que en el fons no és gaire diferent del nostre.

6 Sobre aquest tema, vegeu Rieger (1988), Meneghetti (1989), GRLMA II/1.7 (1990: 384-421), Meneghetti (1991), Poe (2000a), Noto (2006) i Petrossi (2009).
Els textos alludits han generat una bibliografia molt rica i al pas del segle XIX al XX van constituir un dels punts clau de la polèmica encesa a l'entorn del trobador Sordello - a un pas de resultar en un duel veritable- entre Cesare De Lollis i Francesco Torraca? Van interpretar literalment les coblas per tal de resseguir i datar els desplaçaments dels trobadors que hi participen i, més en general, reconstruir-ne la biografia. ${ }^{8}$ Posteriorment, seguint algunes consideracions de Marco Boni (1954: XXIV), que les va llegir per primer cop com a «pure finzioni letterarie, dettate dal desiderio di dar prova di abilità, o esercitarsi nella poesia satirica e realistica», Gianfranco Folena va escriure amb agudesa:

Questi diverbi e improperi giullareschi ai quali il giovane Sordello si trova mescolato sono indubbiamente fra loro collegati nei riferimenti interni e nella tradizione «marginale» (hapax di H e talora di P) [... . e hanno un significato ambientalmente e anche cronologicamente unitario: si tratta di un gruppo di giullari vaganti che si rappresenta in buffoneschi colpi, duelli e risse da taverna, che si collocano probabilmente tra la fine del '2o e il '21; riferiscono fatti memorabili avvenuti a Firenze e a Brescia, 9 e non c'è certo bisogno per questo di collocare questaccademia picaresca in una di queste città né di pos-

7 La bibliografia moderna comença amb l'aportació de Bartsch (1978: 197-198); les primeres edicions crítiques amb comentari són de Levy (1880) i De Lollis (1896); entre altres treballs importants cal destacar Bertoni (1915: 75 i 83), De Bartholomaeis (1931, I: 250 i Il: 61-63, 76-78); Ugolini (1939: XXVIII-XXIX); Shepard \& Chambers (1950: 20-22); Boni (1954: XVII-XXVII); Folena (1976: 474-478 i 498-505); Perugi (1988); Mancini (1991); Gouiran (1993); Poe (2000a i Poe 200ob: 54-63); Caïti-Russo (2005: 121133); Rossi (2005); Gouiran (2006); Guida (2006); Gouiran (2008); Guida (2008: 159-161); Petrossi (2009: 32-34 i 229-232); Negri (2010) que discuteix la bibliografia anterior sobre «questa decina di testi d'occasione» i Negri (2012: 16-20).

8 De Lollis (1896: 4-7); Torraca (1896: 1-9); Guarnerio (1896); De Lollis (1897: 125-151); Torraca (1898); sobre la polèmica vegeu el resum de Stefanelli (2015: 295-319).

9 Brescia és esmentada al v. 2 de la tenso breu BdT 217.4C 10.36; Florència al v. 4 de la cobla de Paves, però cal recordar el suggeriment de Saverio Guida aprofitat per Negri (2010: 2, n. 2): «La località di Firenze [...] andrebbe più adeguatamente sostituita, secondo Saverio Guida (comunicazione personale), con la località Fiorenzuola, vicino a Piacenza». 
tulare col De Lollis un soggiorno fiorentino di Sordello; avranno operato in qualche località padana, a cavallo dell'asse trobadorico allora così attivo fra Malaspina ed Estensi (Folena 1976: 504).

D'altra banda Mancini (1991: 48-49) fa notar com l'abbassamento dello stile, l'abbandonarsi al livello comico, oltre che riflesso di probabili reali schermaglie e mordaci scambi dibattute [...], è soprattutto un fatto letterario. Costituisce, rispetto allo stile alto, una sorta di rovesciamento speculare, e si inserisce in una tradizione retorica»). Mentre que Negri (2010: 11-12) subratlla fins a quin punt depèn d'uuna visione rigidamente deterministica pensare a queste composizioni come a testi concertati insieme e riflesso, sia in termini di identificazioni di trovatori che di rispecchiamenti reali, di un fatto localizzabile nel tempo e nello spazio.

Al nostre grup de set coblas hi destaca un nucli que comparteix un tema comú: un cop d'arma donat o rebut que va provocar una ferida més o menys greu, i que dóna lloc a befes mordaces, insults i recursos retòrics per generar altes expectatives entre el públic, que després desencadenen la riallada. En tres casos es tracta d'una arma impròpia: un pa sec i dur clavat pel Capitanis a l'ull de Guillem l'enojos, segons la narració de Paves (BdT 320.1); una giuncata (un tipus de formatge) Ilençada per Jacopis al cap de Guillelm Testa-pelada, si ens refiem del relat de Figueira (BdT 217.1a); i una gerra dirigida al cap de Sordello, com recorda Aimeric de Peguilhan (BdT 10.7a).

La crítica, preocupada en primer lloc per establir si els cops de formatge, de pa, de gerra i d'espasa es referien a la mateixa baralla o no i després orgullosa d'haver-ne descobert les inconsistències factuals, no sembla haver reflexionat prou sobre les raons que van dur els «rimatori occitani raminghi» (Guida 2008: 167, 'els rimaires occitans rodamóns') a collocar aquestes manifestacions caricaturesques de violència física en un context tavernari al centre d'unes coblas de vituperi ni sobre el seu significat. És possible que la celebració d'aquestes justes reals o imaginàries no siguin més que una troballa retòrica genial i enginyosa, que s'ha de posar al costat d'altres modalitats adoptades pels poetes per acusar-se recíprocament de pertànyer a les files de la joglaria, entesa no tant com un estatus professional amb connotacions neutres sinó més aviat com una condició infamant de dependència de la riquesa aliena, comparable quasi amb la mendicitat. Pensem, per exemple, en els casos en que l'acceptació de donatius per part d'un senyor fa sobreentendre l'etiqueta de joglars i esdevé el punt de partida de preses de pèl malicioses, o bé en textos on la rialla es provoca per allusions a deformitats físiques i amputacions que «sono senza dubbio da leggersi in relazione alle consuetudini giudiziarie vigenti nei confronti dei malfattori»> (Noto 1998: 189-191 's'han de llegir sens dubte en relació als costums judicials vigents respecte als malfactors'). Recordem també, com feia notar Boncompagno da Signa en el Cedrus (1201), que els joglars feien servir «nomina iocosa [...] vel quod per diversitatem nominum sint magis famosi aut quod de suo nomine trahant materiam conjogandi, aut audentis provocentur ad

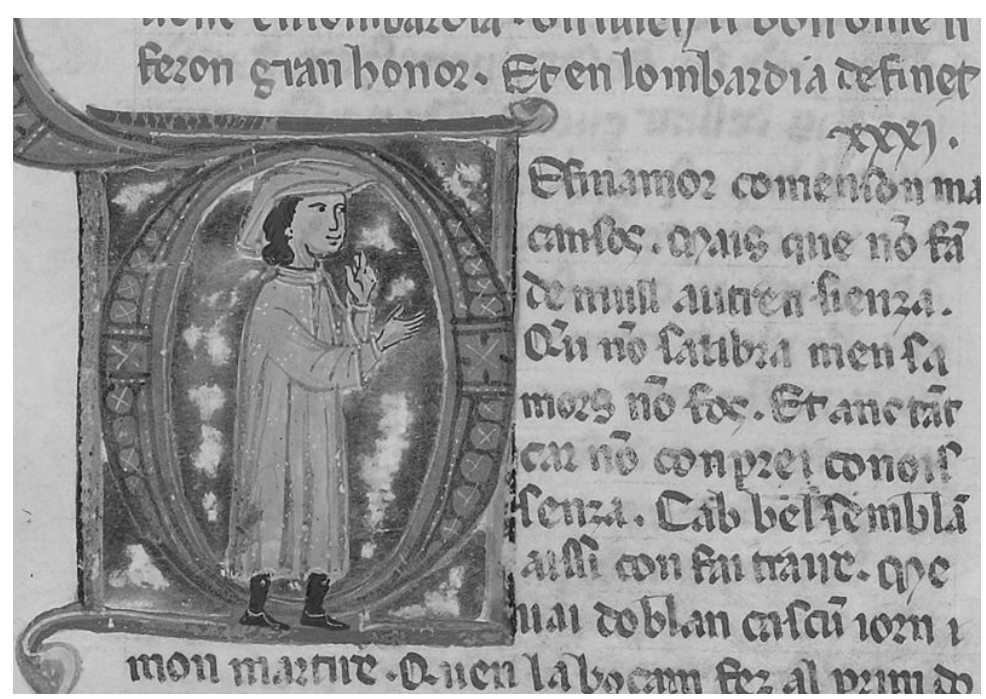

El trobador Aimeric de Peguilhan al cançoner I (París, BnF, fr 854, f. $50 \mathrm{v}$ ).

risum» (Bonifacio 1907: 31 'malnoms [...] bé perquè són famosos gràcies a la varietat dels noms o perquè del nom en treuen matèria per fer befa o fer riure el públic'). Així s'expliquen denominacions com Testa-pelada, Gauta-segnada, Reculaire, 
Budel, Conplit-Flor, Amador, Cantarel, Trufarel, Messonget, etc. És un tema literari, doncs, a incloure entre els Riflessi di costumanze giuridiche nell'antica poesia di Provenza sobre els quals escrivia Giulio Bertoni (1927: 183-212).

Cal tenir en compte, finalment, tot el que assenyala Bonifacio (1907: 20) sobre les disposicions promulgades per Frederic II a Messina el maig de 1221, recollides a la Chronica de Riccardo da San Germano:

Imperator [...] quasdam ibi statuit ascisias observandas contra lusores taxillorum et alearum nomen Domini blasphemantes, contra ludeos, ut in differentia vestium et gestorum a christianis discertantur, contra meretrices ut cum honestis mulieribus ad balnea non accedant et ut earum habitatio non sit infra menia civitatum, contra ioculatores obloquentes ut qui in personis aut rebus illos offenderit, pacem non teneatur imperialmen infringere nec proinde ab aliquo puniatur. $(\mathrm{MGH}, 53, \mathrm{s.}$ III: 47) 10

[L'emperador [...] va establir allí que s'observessin lleis contra els jugadors de daus que blasfemen contra el nom de Déu; contra els jueus, per tal que es distingeixin dels cristians en vestits i comportament; contra les meretrius, perquè no accedeixin als banys de les dones honestes i no tinguin les cambres contra el mur de la ciutat; contra els joglars insolents per tal que qui els danyi en la persona o les propietats no es consideri que interromp la pau imperial i per tant no sigui castigat per ningú.]

Entre les ordenacions municipals promulgades en territori italià al Ilarg del segle XIII, Bonifacio (1907: 86-87) cita els Statuta civitatis Eporediae de 1237, en els quals s'establia que

[...] si aliqua meretrix vel ribaldus, joculator vel ioculatrix, saglobator vel saglobatrix, furiossus vel mentecaptus [...] dixerit vel fecerit quod non placeret eidem bone persone liceat ei et cuilibet alii persone eos verberare etiam usque ad effuxionem sanguinis sine incursu alicuius pene vel banni nisi ex ea verberatione vel percussione aliquis predictorum esset in periculo mortis. (HPM, II: 1212)

[Si alguna meretriu o ribald, o joglar o joglaressa, un o una saltimbanqui, algun furiós o foll [...] digués

10Text reproduït també per Huillard \& Breholles (1852, II/1: 178). o fes alguna cosa que no plau a una bona persona, aquesta o algú altre el pot colpejar fins a fer-lo sagnar sense incórrer en cap pena o condemna, si no és que el cop comporta perill de mort.]

A Ivrea, el joglar que hagués pronunciat paraules injurioses o causat molèsties a un ciutadà acomodat podia ser perseguit per l'ofès o per tercers fins al vessament de sang, sempre i quan no se'l matés. De manera similar, a Siena, entre les venjances privades que no eren penades s'hi consideraven «coloro e' quali battessero, ma pertanto non con ferro, giollaro per villania overo ingiuria la quale loro dicesse») (Elsheikh 2002, II: 420 'aquells que colpegin, però no amb espasa, algun joglar per la seva vilania o per alguna injúria que els hagués proferit'). Similarment, a Vercelli els Statuta del 1241 afirmen:

De zuglariis autem et zuglaresis et meretribus dictum est si iniuriam dicendo vel faciendo alicui de civitate nostra vel de districtu nostro propter hoc verberati vel percussi absque gladio fuerint, tunc ille qui verberaverit vel percusserit solvat bannum solidorum quinque si reclamum inde fuerit potentati. (HPM, XVI/2: 1113)

[Dels joglars i de les joglaresses i de les meretrius s'ha dictaminat que si fessin o diguessin alguna injúria a algú de la nostra ciutat o districte i fossin colpejats o ferits, però no amb espasa, llavors qui l'hagi colpejat o ferit ha de pagar una multa de 5 sous en cas que es faci una denúncia a les autoritats.]

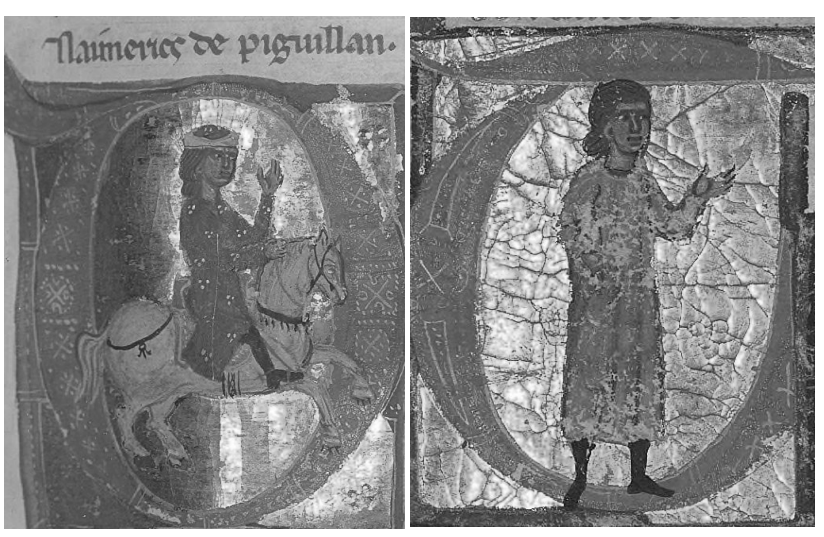

Els trobadors Aimeric de Peguilhan i Sordello al cançoner K (París, $\mathrm{BnF}$, fr 12473, f. 37 i 109). 
L'estatut dels trobadors als castells i les ciutats de la Itàlia centroseptentrional potser només és parcialment comparable al dels joglars professionals: en la nova realitat que hem de considerar les corts senyorials són molt receptives amb el trobar, però les ordenacions municipals prohibeixen la joglaria o hi posen restriccions. Com a única resposta, els trobadors es mostren particularment inclinats cap a la befa recíproca, usant els malnoms abans citats, representant-se l'un a l'altre com a joglars de baixa estofa i com a diana de les reaccions violentes $\mathrm{i}$ impunes dels destinataris de les seves maledicències. Què hi ha de veritat en aquestes baralles és difícil de dir: 'única ferida veritable d'arma blanca sembla ser el cop d'espasa que va ferir la galta de Figueira, tal i com canten Aimeric i Sordello, però la poca cautela a l'hora de mencionar el responsable (n'Auziers) probablement indica que Guilhem Gauta-segnada no va patir conseqüències massa greus i que l'espazada era ben merescuda, ja sigui per un deute impagat o potser pel mal costum de calumniar al.ludit a la cobla esparsa BdT 437.33.

També en les coblas d'escarni que hem deixat fora del nucli estudiat i en sirventesos i tençons de més volada, el menyspreu a la joglaria, amb totes les seves modulacions, es combina amb l'èmfasi sobre els defectes físics o de caràcter dels personatges. De tots els protagonistes sempre se'n critiquen els mateixos defectes, que es converteixen, doncs, en elements que els identifiquen: Aimeric és ridiculitzat com el més vell del grup i se l'acusa principalment d'avarícia, vanitat i oportunisme,"11 a Figueira se'l qualifica de manera unànime com a fals, mentider i maldient; ${ }^{12}$ de Sordello en destaquen sempre l'afició al joc, que el converteix en un joglar que no té mai ni cinc i en un «truffatore emerito» (Folena 1976: 499 'un gran trampós'). En els versos contra-n Sordel s'entreveuen també allusions camuflades a la seva escassa virilitat i a la seva presumpta homosexualitat. La dependència del joc i dels préstecs pecuniaris s'evidencien en particular a la breu tençó entre Figueira i Aimeric (BdT 217.4C 10.36; text 1)

11 BdT 217.1b (text 2/I) i 437.3a (text 6/II), al qual s'afegeixen les dues coblas d'Uc de Saint Circ «Antan fez coblas d'una bordeliera» (BdT 457.5).

12 BdT 10.13 (text 2/II), 280.1 (text 2/III) i 437.33 (text 5). i l'anònima 461.80 (text 7), en la qual el retrat de tafur impenitent està perfectament entrellaçat amb les acusacions d'homosexualitat i de covardia, també presents a 10.7a (text 6/I). Igualment podríem recordar el retrat de Sordello al celebèrrim sirventès de Peguilhan Li fol e-il put e.il filol (BdT 10.32, vV. 9-16):
Greu m'es car hom lor o col
E non lor en fai revel.
Non o dic contra.N Sordel,
Q'el non es d'aital semblan
Ni no.is vai ges percassan,
si co:il cavallier doctor;
mas qan faillon prestador,
non pot far cinc ni sieis terna.
(vv. 9-16, Shepard - Chambers 1950: 166)

[No suporto que els acullin sense protesta. No ho dic contra en Sordello que no és d'aquesta mena, que no hi va buscant guanys com els cavallers doctors; però quan li fallen els prestadors no pot fer una terna amb cinc o sis.]

I, si té raó Guida (2006), la tençó «Scometre·us vuoill, Reculaire» (BdT 458.1 417.1), iniciada per un tal Uguet (Uc de Saint Circ), també representa el mantuà com a joglar escurat i obsessionat pel joc, amagat a sota del pseudònim Reculaire. Segons Guida, es tracta d'un malnom que fa referència a la pràctica de la sodomia, sota el qual hi podem descobrir Sordello (vegeu el requadre a continuació):

\section{Reculaire}

Sobre el terme Reculaire, Guida (2016: 109 i 123) afirma que «sembra lícit traduir-lo «fuori d'ogni puritanismo, con 'reculatore, ri(n)culatore, dietreggiachiappe, paraculo, culattone'» i que «permette di accennare senza imbarazzo ai traviamenti, agli esercizi e ai disvalori della sodomia». Aquest és el poema on aquest personatge debat amb Uc de Sant Circ:

I. Scometre-us vuoill, Reculaire: pois vestirs no.us dura gaire, de paubretat etz confraire als bons homes de Laun, 
mas de fe non semblatz un,

que vos etz fols e jogaire

e de putans governaire.

II. N'Uget, auzit ai retraire qu'uns tenps er, ço m'es vejaire, que l'aursfres e.il gris e-il vaire n'iran ab lo fum tot un; per qu'ieu non ai mon estrun en aver, don sui burlaire; a chascus degra aissi faire.

III. Reculaire, fols seria totz hom que d'aiso's creiria. Vos cuidatz que be-us estia quand al joc vos despoillatz, e can fai freich tremolatz, e cridatz: «Qui·m prestaria son mantel, q'ieu lo:il rendria!»

IV. N'Uget, ben sai, s'ieu moria, c'atretan m'en portaria co.l plus rics reis qu'el mon sia; per qu'ieu sec mas volontatz, e jogui ab sos tres datz e prend ab los conz paria e ab bon vin on q'ieu sia.

V. Reculaire, qi·us donava cinc solz, e pois en gitava altres cinc porr en la grava, detz solz auria perdutz; mentre c'aissi viuretz nutz no-us cuidetz, si be-us estava, vos preses si-us encontrava.

VI. N'Uget, ben paraulla brava m'avetz, cum si re-us costava mos jocs; e s'ieu amassava tal aver don fos perdutz l'esperitz ni deceubutz, dirion que mal estava -l bon homen de Calatrava.

VII. Reculaire, eu sui drutz de tal, si dire l'ausava, qu'es la gensser c'om mentava.

VIII. N'Uget, et ieu vau si nutz que, laire si m'encontrava, no'm tolria si no'm dava. (Riquer 1972: 485-486)
Finalment, podríem pensar en el concís diàleg entre Joan d'Albuzon i el mantuà, «Digatz mi s'es vers zo c'om brui» (BdT 265.1a 437.10a), que s'inicia precisament amb una acusació contra Sordello de ser un joglar, on els dos contrincants s'acusen mútuament de joglaria (vegeu el requadre següent). En relació als motius comentats fins ara, destaca la insistència amb què Joan afirma que Sordello ha rebut vestits com a donatius, per exemple del marquès d'Este, així com la predisposició de Sordello a combatre i les insinuacions sobre la seva homosexualitat. ${ }^{13}$

\section{Joan d'Albuzon Sordello «Digatz mi s'es vers zo c'om brui» (BdT 265.Ia 437.10a)}

I. «Digatz mi s'es vers zo c'om brui, Sordel, q'en don prenetz l'altrui». «Joan, lo joi c'amors madui de l'autrui moiller non refuì. «Sordel, paubertatz vos condui, zo diz om, en joglaria».

«Joan, d'alre joglars non sui, mas de ben dir de mamia».

II. «Pos joglars non es, com prezes, Sordel, antan draps del marqes?». «Joan, eu non l'o prezi ges mas per creisser joglar d'arnes». «Sordel, tal joglar en cregues q'eu sai qe·us sec noig e dia». «oan, per amor sui cortes e donei, e·m combatria».

III. Sordel, re no vos vei donar, mas e.us vei qerer e preiar». «Joan, molt enoios joglar ai en vos, no.| vos puesc celar». «Sordel, [lo] vostre mendigar blasm'om fort en Lumbardia». «Joan, no vos auz encolpar d'enjan ni de fellonia».

13 Vegeu Guida (2006: 114-115) sobre les insinuacions iròniques de BdT 344.3a i 189.4 i Gonçalves (2000) per a la tençó entre el trobador portuguès Johan Soarez Coelho i el joglar Picandon (de picar 'sodomitzar'), al servei de Sordello. 
IV. «Sordel, vos respondetz molt gen,

a lei de joglar aprenen».

«Joan, eu respon avinen

s'es qui m'entenda d'avinen».

«Sordel, moiller trobatz truep len

e ges no sai per qe sia».

«Joan, q'aicil, en cui m'enten,

máam'e $n \cdot i$ vueil compagnia».

\section{Un anònim destre amb el vers i el coltell}

Arribem amb tot això a la setena cobla del nostre recull, obra «di un anonimo che sapeva maneggiare bene il verso, oltre che il coltello» (Folena 1976: 505), i conservada al cançoner P. En primer Iloc, seria interessant confirmar el lligam amb les composicions dialogades que hem vist, produïdes a l'«accademia tabernaria» (Folena 1976: 504) i anteriors a la fugida d'Itàlia de Sordello, no només per l'afinitat temàtica sinó també perquè, «in mancanza d'altri men vaghi, può valere il criterio dell'attiguità di due componimenti relativi a una stessa persona in un canzoniere» (De Lollis 1896: 7, 'en absència d'altres de menys vagues, pot valer el criteri de la contigüitat en un mateix cançoner de dos poemes referits a la mateixa persona'). Ens hem d'aturar a analitzar la tradició manuscrita d'aquestes peces perquè la seva especificitat ha fet pensar que el cercle de poetes coincidia amb el del públic,14 i això en va condicionar la circulació manuscrita: una difusió limitada, corroborada pel fet que moltes ens hagin arribat en un sol manuscrit.

Pel que fa als unica de $H$, Elizabeth W. Poe (200ob: 43-71) demostra de manera convincent que la tercera part del cançoner vaticà — definit com a parvus per Pietro Bembo- no deriva, com pensava Gröber, d'una collecció orgànica preexistent $\left(H^{3}\right)$ sinó que és més aviat el fruit d'una operació complexa de compilatio per part del copista. Poe identifica tota una sèrie de fonts d'aquesta tercera secció que corresponen a petites colleccions independents de què devia disposar el copista. Extraient-ne els materials que li van semblar més interessants, els va disposar tal

14 Vegeu Meliga (2003: 98) i Guida (2006: 110-111). i com apareixen avui a $H^{3}$, remarcant i donant un nou significat als textos precisament per les connexions que aquesta disposició provoca. Entre les moltes aportacions importants d'aquesta recerca, ara només ens interessa de subratllar que Uc de Saint Circ és el trobador dominant a $H^{3}$ (el manuscrit reprodueix divuit textos i excerpta atribuïts al caorsí, deu dels quals són coblas d'argument satíric que no es copien en cap altre testimoni) i diverses de les fonts menors a què va tenir accés exclusiu el compilador van ser de manera versemblant aplegades pel mateix Uc, fins al punt que «we are left with the nagging suspicion that Uc's influence on the compilation of MS H was more than casual» (Poe 200ob: 257 'ens queda la sospita persistent que la influència d'Uc sobre $H$ no va ser només casual).

Entre els materials amb circulació limitada o nulla que posseïa el compilador, potser arribats directament de mans d'Uc i que per això no van acabar en altres cançoners, al costat de les colleccions organitzades per nuclis temàtics, n'hi ha d'altres d'estructurades a partir de la juxtaposició d'un text amb tota una sèrie de contrafacta. Poe n'ha identificat tres, basades en models mètrics i melòdics originals de Gui d'Ussel, Bertran de Born i Peire Vidal, respectivament. Al petit recull de Gui d'Ussel i dels seus imitadors hi pertany la cadena de coblas BdT 217.1b $10.13 \sim 79.1 \sim$ 280.1 (text 2). L'esquema prové de «L'autre jorn cost'una via» (BdT 194.13), la pastorela que va servir de model a l'intercanvi polític entre Gui de Cavaillon i el comte de Tolosa (copiat al f. 52r de $H),{ }^{15}$ al nostre tornejament (transcrit tot seguit al mateix foli) i també a l'intercanvi entre Uc de Sant Circ i Guilhem del Baus (un altre unicum de $H$, ff. 53v-54r). ${ }^{16}$ La cobla de Paves (text 3), inspirada en l'estructura formal del sirventès-cançó «Pos Ventadorns e Comborns ab Segur» (BdT 80.33), s'hauria de remuntar a una font similar amb models originals i imitacions de Bertran de Born. Finalment, la cobla de Figueira (text 4/I) -amb la resposta d'Aimeric de Peguilhan (text $4 /$ II) - imita

\footnotetext{
15 Seigner coms saber volria $\sim$ Per deu Gui mais ameria (BdT 192.5 186.1).

16 Physica et astronomia [L]iautatz ses tricharia (BdT $457.30 \sim 209.3)$.
} 
la cançó de Raimon de Miraval «Chan, quan non es qui l'entenda» (BdT 406.22).17

Tot això no impedeix d'explicar la proximitat material entre l'estrofa de Paves i les dues següents perquè, fins $i$ tot admetent que cap de les tres derivi d'una font del tipus original+contrafacta, és possible pensar que el copista les hagi acostat a la tençó precedent a quatre veus, amb la qual en comparteix dues. Dit això, la consistència codicològica de BdT $320.1 \mathrm{amb}$ les dues coblas posteriors no em sembla un factor menor, encara que sigui impossible assegurar si l'antecedent ja agrupava els tres poemes — com deixa entendre el tractament de la mise-en-page que han assenyalat els estudis crítics. En aquest cas potser són el reflex d'una lluita poètic de baix nivell, que podria obeir a la seqüència següent: Figueira s'incorpora al concurs de destresa poètica iniciat per Paves, tot retraient, amb un esquema mètric diferent, una divertida anècdota sobre Guillem —que Folena (1976: 503) va definir com el cap de turc. Aquest personatge és l'enoios de Paves i el Testa-pelada de Figueira, i fins ara ha resistit totes les temptatives d'identificació. A la intervenció de Figueira hi replica divertit Aimeric, que no perd l'ocasió de posar-lo totalment en ridícul, fent-li notar com ell mateix, Guilhem Gautasegnada Figueira, que s'ha guanyat — pel que sembla, de veritat- una cicatriu a la galta, no es pot permetre de riure dels cops de formatge dels altres. El mateix mecanisme (i la mateixa cicatriu) són, de fet, a la base de la rèplica d'Aimeric a la demanda insolent que Figueira havia dirigit a Bertran d'Aurel. En qualsevol cas, tant si prova de començar una discussió, com de participar en les rialles contra un personatge desconegut que du per nom Guillem, Aimeric de Peguilhan va fer callar burlescament Figueira, i la rialla que aquest havia intentat provocar amb els seus versos se li gira en contra.

Hem recordat que a l'origen d'aquest gènere de textos breus i dialogats sembla que hi hagi

17 Segons Poe (200ob: 63 i 70, n. 69), aquestes últimes serien imitació de BdT 80.18. Vegeu però la fitxa BdT 217.1a a la Bibliografia Elettronica dei Trovatori de Stefano Asperti (http://www.bedt.it/ —última consulta 22-062016).

18 Negri (2010: 6-7), en la línia de Careri (1990: 436). peces improvisades en les quals els interlocutors retreien un aspecte molt conegut per formular atacs ad hominem o per fer sàtira política. En aquest cas, potser podem atribuir a Uc de Saint Circ l'inici dels reculls de tipus original + contrafacta, dels quals no sobreviu cap testimoni, però que s'entreveuen en l'operació de desmuntatge de $H^{3}$. ¿Podria ser que Uc hagués col·leccionat peces poètiques menors i extemporànies de trobadors contemporanis, que freqüentaven els mateixos ambients italians que ell i practicaven el mateix gènere de cobla satírica? Si no és que gosem afirmar que Uc devia assistir en primera persona a alguns d'aquests desafiaments i els va posar per escrit...

No hi ha dubte, en canvi, sobre la relació personal i recíproca entre els autors d'aquestes colleccions de coblas, corroborada per un dens diàleg intertextual, que afecta també peces d'altres gèneres lírics. Així la breu tençó que obre la sèrie relacionada amb la «scapigliatura estense» (Folena 1976: 500 'la bohèmia d'Este') presenta una contigüitat mètrica amb el text immediatament anteri-

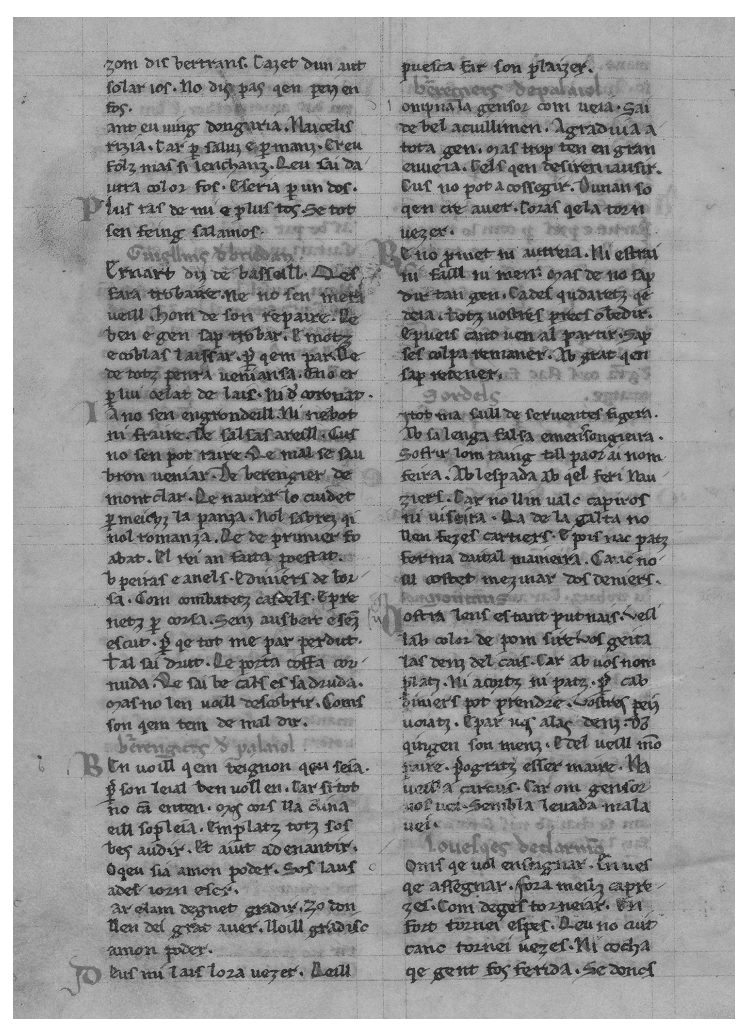

El f. 52 r del cançoner $H$ (Roma, Biblioteca Vaticana, Lat. $3207)$. 
or al f. $50 v$ de H, és a dir el diàleg polític i cortesà entre Guilhem Raimon i Aimeric de Peguilhan. Segurament aquest diàleg és el punt de partida de Figueira, per acabar desplaçant l'atenció cap a una partida d'escacs entre Bertran d'Aurel i Guillelm del Dui-Fraire que podia haver acabat en homicidi. El primer dels dos desafiants, a més de ser l'executor del testament burlesc que és objecte de la sèrie de coblas, és probablement també el Bertran reclamat per Guilhem Augier Novella (Calzolari 1986: 43-44) al partimen «Bertran, vos c'anar soliatz ab lairos» (BdT 205.1 79.1a), unicum del cançoner $E$ (BnF, fr. 1749), que tracta del tema «qual mestier es plus aontos, d'esser jotglar ho laire» 'quin ofici és més vergonyós el de joglar o el de lladre', i que indubtablement s'adreça a les corts de l'Itàlia del nord (Menichetti 2013: 223).

Una selecció d'aquesta mena es deu haver produit també en les tres unitats que van confluir al cançoner P. Les coblas van seguides una darrere l'altra a la columna de la dreta del f. 55r, separades per una ratlla en blanc, totes anònimes. L'intercanvi entre Aimeric i Sordello pertany a la matriu procedent de la cort d'Este, identificada per Asperti (1995: 166), que constitueix una aportació petita però compacta (vg. requadre de la dreta). Aquest diàleg està precedit per quatre unica (BdT 461.170, 461.183, 461.173 i 461.162) centrats sobre el tema de l'aver i sobre les qualitats morals del ricx (Noto 2010), que proposa assignar les dues primeres a Bertran Carbonel), i d'una cinquena cobla transmesa també pels cançoners $G$ i $F^{19}$ per a la qual s'ha suggerit una atribució a Raimon Bistortz d'Arles perquè la cobla (BdT 416.13) està dedicada a Costanza, filla d'Azzo VII d'Este i obre el «nucleo di componimenti legati in vario modo alla corte estense [...] nelle cui tradizioni si presentano ripetutamente analogie o parallelismi con il canzoniere H» (Asperti 1995: 166 'nucli de composicions lligades de diverses maneres amb la cort d'Este [...] en les tradicions de les quals hi ha analogies o paralel-lismes recurrents amb el cançoner $H^{\prime}$ ). A aquest nucli s'hi poden reconduir les nostres tres pièces bohèmies,

19 Biblioteca Ambrosiana, R 71 sup. i Biblioteca Apostolica Vaticana, Chigi L. IV, 106. i també l'intercanvi entre Falco i Cavaire (BdT 151.1 111.2) transmès per $P$ i $H$, en el qual els dos joglars (un dels quals, cal recordar, era mutilat) alludeixen al marquès d'Este.

\section{El nucli de poemes provinents de la cort d'Este al cançoner $P$}

A banda dels poemes esmentats, Asperti inclou en el grup l'intercanvi més tardà entre Raimon Guillem i Ferrarino da Ferrara (BdT 229.1a 150.1) perquè està construït sobre el descort isoestròfic d'Aimeric de Peguilhan Qui la ve en ditz (BdT 10.45). Afirma que «Questa componente "estense", di cui troveremo un ulteriore prolungamento più oltre sempre nella sezione di coblas di $P$, risulta interessante $[. .$.$] in$ rapporto ad altri testi confluiti nel codice laureziano (certamente il Donat e il glossario, forse le Vidas, codicologicamente indipendenti). Riguardo a quest'ultimo aspetto, va senz'altro acquisito come dato rilevante e tipizzante il fatto che materiali importanti aventi la medesima origine siano utilizzati in più luoghi distinti del canzoniere, così da conferire all'insieme una prima coerenza di "tradizione". Infine, i testi che compaiono in questa zona iniziale non oltrepassano mai sull'asse cronologico i primi anni '40 [...]; di nuovo, questo dato di massima corrisponde bene a quanto riscontrato sia in $F$ riguardo al nucleo costitutivo del florilegio, sia anche in H». (Asperti 1995: 167)

En resum, doncs, aquestes tres coblas haurien viatjat plegades, amb altres materials d'ascendència vèneta, per acabar, després d'un itinerari que potser passava per Gènova i els territoris dels Malaspina (Asperti 1995: 189 i Resconi 2014), primer a la Toscana (fan pensar en Florència particularment el glossari i altres unitats de la secció de coblas) i més tard l'Úmbria, fins a I'scriptorium situat a Gubbio on el copista Pietro Berzoli va transcriure la col·lecció de cançons i sirventesos (ff. 1-38), les coblas (ff. 55-66), les gramàtiques i el glossari.

Arribats a aquest punt, iés lícit preguntar-se com és que un grup textual tan compacte ha acabat dispersant-se en les sèries dels cançoners H i P? ¿Té sentit preguntar-se per què les 
tres unitats de $P$ no van acabar a $H$ ? Diria que no. Hem de recordar, de fet, que $H$ és un esborrany de treball incomplet i que una de les llacunes afecta precisament els fulls del plec immediatament anterior al dels intercanvis de què parlem. En l'estat actual de la nostra recerca no podem saber si l'intercanvi entre Aimeric i Sordello i la cobla anònima es van copiar sobre els fulls que s'han perdut, com passa amb la tenso entre Falco i Cavaire preservada per accident en tots dos còdexs. Seria més interessant, si de cas, preguntar-se quin sentit té la seva presència a $P$, dins d'una secció dominada per la collecció de Bertran Carbonel, plena de coblas anònimes d'empremta burgesa i ciutadana, sensibles a l'actualitat política i que es poden datar molt a prop de la composició del cançoner.

Sobre la reconstrucció de la composició dels plecs vegeu Careri (1990: 6-28), de la qual cal remarcar que «il manoscritto è composto di nove fascicoli: quattro quaternioni più cinque -irregolari e lacunosi- ricomposti in seguito ad interventi di restauro» (p. 7) i que «non trattandosi di un codice copiato in un'unica e ordinata fase di trascrizione, l'analisi della fascicolazione va continuamente confrontata con una serie di altri dati inerenti alla "cronologia relativa" delle carte» (p. 6). Segons els primers estudiosos del cançoner, $H$ hauria estat format originàriament per onze plecs. Per De Lollis (1889) avui el còdex hauria perdut 26 fulls, que serien més de 22 per a Gauchat \& Kehrli (1891).

En aquest sentit em sembla fonamental, com fa notar Asperti (1995: 167), que un factor recurrent en aquestes coblas és la presència d'Aimeric de Peguilhan com a autor, «ed anche, in forma mediata, attraverso il suo schema metrico-musicale più originale e complesso, ripreso nella tenzone fra Ferrarino e Guillem Raimon» ('i també mitjançant el seu esquema mètrico-musical més original i complex, reprès per la tenso entre Ferrarino i Guillem Raimon'). En efecte, una canso d'Aimeric de Peguilhan (BdT 10.33) és el tercer text del còdex, tot i que queda atribuiida a Blacasset. Una mica després es pot llegir una altra peça seva (BdT 10.8), també amb un error atributiu a Giraut de Borneil; ben al contrari, Aimeric té una colllecció pròpia als ff. 11V-13r, on s'agrupen set textos (BdT 10.41, 10.17, 10.50, 10.12, 10.27, 10.15-el primer amb la rúbrica Gaubert) i finalment al f. $34 r$ es copia com a anònima la seva composició BdT 10.46, just abans de tres textos d'Uc de Saint Circ. En el plec independent de vidas i razos (ff. 39-54), copiat per una altra mà, s'hi ha transcrit la biografia antiga: Bertelli (2004) ha identificat el responsable de la secció biogràfica amb una de les mans actives al manuscrit Martelli 12 de la Laurenziana, un testimoni dantesc important amb el qual el nostre cançoner $P$ comparteix tres copistes. Si fem cas d'una proposta recent de Fabrizio Cigni (2016) podria ser aquest, i no Pietro Berzoli com s'havia suposat, el responsable de la unió de les diferents parts del cançoner en un organisme coherent que el converteix en un «vero e proprio Manuale d'avviamento agli studi provenzali» (Cingolani 1988: 113). ${ }^{20}$ A més de BdT 10.7a, aquesta antologia recull tres coblas triadas de la cançó «Ses mon apleich non vau ni ses ma lima» (BdT 10.47) collocades just abans de les unitats 20-72, atribuiides totes a Bertran Carbonel.

És possible, doncs, que la personalitat poètica d'Aimeric de Peguilhan — que en les seves composicions dóna compte de les relacions amb els principals trobadors emigrats a Itàlia — hagi estat el catalitzador del traspàs a $P$ de l'intercanvi d'injúries amb Sordello, igualment ben representat entre les coblas del cançoner de la Laurenziana.

\section{Sobre l'autoria de l'esparsa anònima}

Així doncs, el diàleg mordaç ha atret com un imant l'esparsa 461.80 dirigida al segon interlocutor. A banda de demostrar la connexió entre el grup de coblas, els comentaris precedents també permeten d'oferir algunes reflexions sobre la seva possible paternitat. A primera vista, afavoreixen sens dubte l'atribució a Aimeric, o almenys ens porten a excloure que fos concebuda en un moment o un Iloc gaire allunyats de l'intercanvi

\footnotetext{
20 No és un impediment per a aquesta interpretació la diferència en la transcripció del nom del trobador tolosà: Naimeric de Pepugnan a la rúbrica i l'íncipit de la vida per una banda (f. 51r) i les rúbriques de BdT 10.17 i 10.50 per l'altra, mentre que els textos restants de la secció d'autor s'adscriuen a Naimeric.
} 
entre Aimeric i Sordello. Això permet refutar la proposta de Kolsen (1939: 100, n. 1) que pensa en Peire Bremon Ricas Novas. ${ }^{21}$

Tanmateix entre els atacants més ferotges del jove Sordello hi ha també Uc de Saint Circ i Joan d'Albuzon. El primer podria haver-lo interpel·lat a la tençó «Scometre•us vuoill, Reculaire» i a la dansa «Una danseta voil far» (BdT 457.41), ${ }^{22}$ unicum del cançoner $N$, amb la qual acompanya maliciosament, a ritme de música, la fuga de Sordello d'Itàlia després de l'afer Cunizza i el matrimoni amb Otta de Strasso contra la voluntat dels germans de la dona. En tots dos textos s'hi pot veure una actitud de superioritat per part del caorsí, que mira el jove italià amb menyspreu i no s'està de subratllar-ne els defectes més immorals. No obstant això, Uc no participa en els duels de la «bohèmia» d'Este, si no és com a observador super partes.

Pel que fa a Joan d'Albuzon, el trobador provençal és amb tota versemblança el Çoanet lo menor recordat a la cobla de Bertran d'Aurel (text 2/III), al qual estan dedicats «l'enjan e la tricharia» de Guilhem Figueira, «car el viu d'aital labor» ('perquè viu d'aquesta feina'). ${ }^{23}$ És possible que aquí Bertran estigui alludint a la irònica lítote ideada per Sordello per replicar als insults de la tençó «Digatz mi s'es vers zo c'om bruil»: «Joan, no vos auz encolpar | d'enjan ni de fellonia» (vv. 23-24 'Joan, no goso inculpar-vos d'engany ni de traïció'). Recordem també que Joan d'Albuzon és l'autor d'una composició satírica posterior que ataca Sordello, composta després que aquest hagués marxat d'Itàlia: són dues coblas i una tornada que comparteixen l'estructura mètrica i de rimes (i la rima -reon) de la peça anònima de $P$ (vegeu el requadre següent).

21 Kolsen fonamenta la proposta en l'«affinità di ordine linguistico, perché ritiene di ravvisare nel testo alcuni nessi linguistici con un altro componimento del trovatore, il sirventese 'Lo bels terminis m'agensa' (BdT 330.9), composto in risposta ad un attacco di Sord, contenuto in "Quan qu'eu chantes d'amor ni d'alegrier" (BdT 447.28)» (Petrossi 2009: 230).

22 Ma vida, el senhal reservat al dedicatari de la danseta, ha estat interpretat per Radaelli (2000) com a una nova allusió a la pobresa del trobador (MANU *VocITA); Guida (2006), poc convençut, apunta a una sèrie d'errors de lectura sobre un antecedent que devia dur un Mantoan.

23 La proposta és a Folena (1976: 502) i encara a Rossi (2005: 43).

\section{Sirventès de Joan d'Albuzon contra Sordello (BdT 265.3)}

I. Vostra dompna, segon lo meu semblan, vos contrafatz, bel amic en Sordel; car vos annatz Provenza conqistan Engleterra e Franza e Lunel

E Lemozi, Alvergn'e Vianes

E Borgoign'e totz los autres paes

E d'Espagna los plans e.l pois el mon.

De conqerre tut or vo ser a ffron!

II. Vostra dompna fo al terré denan per conqistar l'emperi Manuel, Ongari'e Cumania la gran,

E Russia conqistet ses revel

Et eissamen lai de mar anet, ges per conqistar l'enperi qe la es, et enaissi conqerretz tot lo mon, se conqerretz d'aval e il d'amon.

III. Amic Sordel, can Gasco e Frances seran amic, adonc vos trobares lei qui cerchas tot lo mon e reon; quant om ve l'un, e l'autre s'en escon. (Kolsen 1939: 100-101)

Només ens queda examinar una última opció: la possibilitat que la cobla de $P$ es pugui atribuir a Guilhem Figueira, com de fet ja va proposar Folena (1976: 505). ${ }^{24}$ Guilhem és un bon candidat a ser-ne l'autor, implicat pel propi Sordello a la cobla esparsa que figura a $H$, a pocs fulls de distància dels altres textos que hem comentat. Aquest últim poema és un atac personal de Sordello contra Figueira, exasperat per les acusacions d'escassa virilitat i d'addicció al joc que molt sovint rebia per part dels trobadors faidit. Encara que no sigui possible datar amb més precisió el text, és extraordinàriament versemblant que els fets alludits $i$ la composició s'hagin de situar cap a 1229, quan es va tancar el primer parèntesi italià de la biografia del mantuà. Figueira, però, és l'únic dels quatre possibles participants de qui no es con-

24 Stefano Resconi ha tornat a formular la hipòtesi en una intervenció amb el títol 'Satura lanx': forme dell'interdiscorsività nella struttura di alcune raccolte di poesia comica romanza en el darrer colloqui de la Società Italiana di Filologia Romanza (Catània, 22-26 setembre de 2015), ara a Resconi (2016). 
serven textos amb acusacions explícites ni befes contra el trobador italià: el tolosà participa en la breu tenso amb Aimeric (text 1) però és aquest darrer qui hi involucra el jove Sordello amb la menció al v. 7. L'íncipit de BdT 437.33 (text 5) em sembla, però, molt interessant: Sordello se'n riu de Figueira alludint a una caracterització de la seva lírica que devia identificar-lo universalment i deixa entendre que la possibilitat de convertir-se en diana d'un dels seus sirventesos no devia ser gaire llunyana. L'acusació de falsedat del v. 2 i l'allusió a un càstig rebut precisament a causa de la seva llengua tallant i bífida ens donen la imatge d'un trobador que llançava sirventesos contra tot i contra tothom, també sense raó, contínuament.

Tot i que hi manca una identitat d'esquema mètric, que impedeix definir aquests dos microtextos com a una cobla amb resposta i encara menys com a un intercanvi, hi ha elements d'afinitat que apuntarien a favor de la hipòtesi de Gianfranco Folena. Es presenta, però, el problema de la forma que cal donar a l'íncipit de BdT 461.80 (text 7): la transcripció diplomàtica llegeix $E$ tot qan ma ofes en aiqest an, amb una $E$ pintada en vermell, d'una alçada de dues unitats de ratllat i filigrana blava. La tinta de la inicial se sobreposa en una petita part a la $t$, traçada regularment en versaleta. La Bibliographie der Troubadours i la BEdT registren el text com si comencés per De tot i segueixen així la proposta de Bartsch (1872: 199). Entre les pièces anònimes, a les quals el Grundriss assigna el número 461, al lloc 80 hi trobem: «(D)e tot qan m'a o fes en aiqest an $(P) »$.

S'ha de dir que no hi ha gaires textos que s'obrin amb una conjunció copulativa, ${ }^{25}$ i que la sintaxi del verb perdonar [alguna cosa a algú] fa inclinar per l'esmena de Bartsch. L'error no és insòlit: al mateix f. 55r hi ha dos errors més a les inicials pintades i afecten les coblas 2 i 3 de la collecció (Allegretti 1993: 206 i Noto 2010: 1-2). És

25 Es tracta de BdT 461.11 i 461.114 (dues coblas anònimes, la segona de les quals és un unicum de $P$ (Petrossi 2009: 304), d'una estrofa extreta del sirventès de Guillem de Berguedà BdT 210.10a, i afegida a la razo corresponent a BdT 80.35 de Bertran de Born copiada a $P$ i de 140.l, el judici del comte Enric Il de Rodés sobre l'exposició de Guiraut Riquier a la cançó al-legòrica de Guiraut de Calanson (Capusso 1989). per tant molt probable que la badada es pugui remuntar a un estadi anterior al copista, ja que en els tres casos Pietro Berzoli sembla que respecti la regla gràfica que preveia dissenyar en versaleta la segona lletra de l'íncipit. Pel que puc veure a la reproducció en línia no hi ha cap lletra guia per al decorador. ${ }^{26}$ Si per contra l'íncipit fos correcte, ${ }^{27}$ ¿es podria pensar en un residu de sirventès aquell amb el qual Figueira hauria atacat Sordello i que no s'ha conservat, com afirmava De Bartholomaeis (1931, II: 62-63)? En realitat l'estrofa funciona perfectament com un epigrama, complet en la seva brevetat i dotat d'una gran força representativa.

Sigui com sigui, no es poden deixar de notar algunes analogies en l'exordi i en la construcció de les dues coblas, que van més enllà del joc de sonoritats produit per la presència a l'inici de Si tot en un cas i E / De tot en l'altre. Les dues unitats s'obren amb la professió de magnanimitat de l'autor davant de l'adversari i el nom del receptor està explicitat a principi de vers en tots dos casos, no pas amb un vocatiu sinó en tercera persona, com si en aquell moment l'altre no hi fos present. L'explicació de l'actitud de tolerància cap al seu desagradable destinatari es desenvolupa al llarg de dues coblas. L'anònim sap que Sordello serà l'artífex del seu propi càstig per les ofenses rebudes, perquè el vici del joc tard o d'hora li costarà la vida: ja s'hi ha jugat de fet els seus dos palafrens i el seu destrer. Per contra, Sordello, pateix la maledicència de Figueira per por de rebre un cop d'espasa com el que el tolosà insolent s'ha guanyat per part de n'Auzers. I és aquí on trobem l'atac frontal, directe al punt dèbil de cadascun dels dos personatges. Per una banda, s'estigmatitzen la passió per les apostes i la manca de virilitat duta a l'extrem: per citar Folena una vegada més, és ben probable que el destrer i els palafrens perduts en el joc siguin cavalls «puramente metaforici», amb intenció d'insinuar la castració de Sordello. Per

26 Es pot consultar a l'Aparador digital de la Biblioteca Laurenziana a l'adreça http://teca.bmlonline.it/lmageViewer/servlet/ImageViewer?idr=TECA0000623982\& keyworks=Plut.41.42\#page/1/mode/1up (darrera consulta 22-06-2016).

27 Així es pot veure a De Bartholomaeis (1931, II: 73), Kolsen (1939: 100) i també Petrossi (2009: 230). 
l'altra, es ridiculitza Figueira amb el record de la memorable ferida a la galta que ja va ser objecte de les sagetes poètiques d'Aimeric de Peguilhan. L'estocada final que tanca la cobla de $P$ és genial i fa explícit el doble sentit obscè: si Sordello arriba a un riu i no troba cap gual o cap pont, s'abaixa les calces i ensenya el seu reon a tothom.

Potser es podria proposar que l'atac l'havia començat Figueira i que la cobla de Sordello constitueix la rèplica a distància. Si fos així, denotaria, de fet, una certa dificultat del contraatac per part del mantuà. Les injúries a l'adversari de seguida després de l'íncipit, l'ús d'una construcció lògicament estrident i no massa sagaç en evocar la por de rebre un cop d'espasa com el que va fer-li Auziers i el final poc clar indicarien que, com apunta Gérard Gouiran (1993: 649-651), «Sordel ne se sentait pas trop à l'aise» ('no se sentia gaire a gust'), i encaixarien amb la seva actitud en la tenso amb Joan d'Albuzon i en l'intercanvi amb Aimeric a $P$, abonant en definitiva la hipòtesi de Folena que acabem de discutir. ${ }^{28}$

La qüestió és impossible de resoldre si no s'obtenen dades noves. A causa de les semblances de constructio dels dos microtextos satírics tenim la sospita fonamentada que qui dialoga amb Sordello és el propi Guilhem Figueira. És impossible, i potser inútil, establir si les peces es van concebre al mateix moment, in praesentia, o si són el fruit d'un diàleg a distància. El que sembla segur és que es troben en l'òrbita de la «bohèmia» d'Este. És ben possible que l'estructura mètrica diferenciada sigui la causa de la seva separació en la tradició manuscrita. Cap dels dos textos no respon, de fet, als criteris que segueix el compilador de $H$ quan tria els materials que refon a la tercera part del recull ni amb la manera de situar-los al foli. Aquesta diferència de protocol formal de les coblas em sembla que podria derivar de la voluntat de l'autor de la rèplica d'adoptar el nom de l'adversari a la rima, exactament com aquest havia fet en el seu.

28 En tots dos casos, Gouiran (1993: 650) afirma que «cet humour grinçant a quelque chose de gênant et je serais tenté de dire qu'il est la caractéristique d'un homme en position défensive, ce que confirme bien le fait que, dans les trois pièces, Sordel est toujours celui qui répond».
No seria lícit anar més enllà. Però sí que seria oportú dedicar més esforços ecdòtics a aquestes dues peces, sobretot a partir d'un estudi aprofundit de la llengua dels dos testimonis d'origen italià, afegint a l'edició un aparat de comentari que sintetitzi tot el que s'ha proposat i amb una traducció adequada. Ens haurem de conformar per ara que aquests pocs versos tan interessants hagin pogut escapar als accidents de la història i que reflecteixin un intercanvi - seriós o burlesc - entre dos personatges que encara dialoguen, parlant-se d'un cançoner a un altre. 


\section{Bibliografia}

AlbARET, Laurent, 2003: «L'anticléricalisme dans les registres d'inquisition de Toulouse et Carcassonne au début du XIV siècle», Cahiers de Fanjeaux, 38, 447-470.

Albaret, Laurent, 2014: «La collection Doat, une collection moderne, témoignage de l'histoire religieuse méridionale des $X I^{1}{ }^{e}$ et $X I V{ }^{e}$ siècles», Cahiers de Fanjeaux, 49, 2014, 57-93.

Allegretti, Paola, 1993: «ll plazer-enueg nella lirica occitanica», Tesi de doctorat, Università di Perugia.

Asperti, Stefano, 1995: Carlo I d'Angiò e i trovatori. Componenti "provenzali" e angioine nella tradizione manoscritta della lirica trobadorica, Ravenna: Longo.

BARTSCH, Karl, 1872: Grundriss zur Geschichte del provenzalischen Literatur, Eberfeld: Friedrichs.

BARTSCH, Karl, 1878: «Ein keltisches Versmass im Provenzalischen und Französischen», Zeitschrift für romanische Philologie, 2, 195-219.

Bertelli, Sandro, 2004: «Nota sul canzoniere provenzale $\mathrm{P}$ e sul Martelli 12», Medioevo e Rinascimento, 18, 369-377.

BertonI, Giulio, 1915: «l trovatori d'Italia», Mòdena: Orlandini.

Bertoni, Giulio, 1917: «Riflessi di costumanze giuridiche nell'antica poesia di Provenza», Poesie leggende costumanze del medio evo, Mòdena: Orlandini, 145-169.

BdT = PILLET, Alfred \& Henry CARSTENS, 1933: Bibliographie der Troubadours, Halle: Niemeyer.

BILler, Peter, Caterina BruschI \& Shelagh SNEDDON (ed.), 2011: Inquisitors and heretics in thirteencentury Languedoc. Edition and translation of Toulouse inquisition depositions, 1273-1282, Leiden -

Boston: Brill.

Boffito, Giuseppe, 1897: «Notizia di letteratura provenzale tratta da un codice parigino», Giornale Storico della Letteratura Italiana, 29, 204-208.

Boni, Marco (ed.), 1954: Sordello, le poesie, Bolonya: Palmaverde.

Bonifacio, Gaetano, 1907: Giullari e uomini di corte nel 200, Nàpols: Tocco.

Boutière, Jean \& Alexander $H$. SCHUTZ, 1964: «Biographies des troubadours. Textes provençaux des XIII ${ }^{e}$ et XIV ${ }^{e}$ siècles. Édition refondue, augmentée d'une traduction française, d'un appendice, d'un lexique, d'un glossaire et d'un index des termes concernant le "trobar"», París: Nizet.

BrusCHI, Caterina, 2003: «Magna diligentia est habenda per inquisitorem: precautions before reading Doat 21-26», Texts and the Repression of Medieval Heresy, ed. P. Biller i C. Bruschi, YorkWoodbridge-Rochester (NY): York Medieval Press-Boydell \& Brewer, 81-110.

CaïTI-Russo, Gilda, 2005: Les troubadours et la cour des Malaspina, Montpeller: Université Paul-Valéry Montpellier III.

Calzoları, Monica (ed.), 1986: II trovatore Guillem Augier Novella, Mòdena: Mucchi.

Careri, Maria, 1990: I/ canzoniere provenzale H (Vat. Lat. 3207). Struttura, contenuto e fonti, Mòdena: Mucchi.

Capusso, Maria Grazia, 1989: L'Exposition di Guiraut Riquier sulla canzone allegorica di Guiraut de
Calanson 'Celeis cui am de cor e de saber', Pisa: Pacini.

Castellani, Arrigo, 1958: «Le glossaire provençal-italien de la Laurentienne (MS. Plut. 41,42)», Lebendiges Mittelalter. Festgabe für Wolfgang Stammler, Freiburg: Universitätsverlag Freiburg, 1-43.

Cigni, Fabrizio, 2016: «Francese e italiano nei canzonieri provenzali. Precisazioni e osservazioni sui casi di $P$ e p», Francofonie Medievali. Lingue e letterature gallo-romanze fuori di Francia (secc. XII-Xv): Atti del convegno internazionale della Società Italiana di Filologia Romanza (Verona, 2014), ed. Anna M. Babbi i Chiara Concina, Verona: Fiorini, 189-208.

Cingolani, Stefano M., 1988: «Considerazioni sulla tradizione manoscritta delle vidas trobadoriche», Actes du XVIII Congrès International de Linguistique et de Philologie Romanes, Trèves (Trier), 1986, Tübingen: Niemeyer, VI, 108-115.

De Bartholomaeis, Vincenzo, 1931: Poesie provenzali storiche relative all'Italia, 2 vols, Roma: Tipografia del Senato.

De Lollis, Cesare, 1889: «Appunti dai manoscritti provenzali Vaticani», Revue des langues romanes, 33, 157-193.

De Lollis, Cesare (ed.),1896: «Vita e poesie di Sordello da Goito», Halle, Niemeyer.

De Lollis, Cesare, 1897: «Pro Sordello de Godio, milite», Giornale Storico della Letteratura Italiana, 30, 125-207.

ELSHeIKH, Mahmoud Salem (ed.), 2002: II costituto del comune di Siena volgarizzato nel MCCCIX-MCCCX, 4 vols, Siena: Fondazione Monte dei Paschi. 
FolenA, Gianfranco, 1976: «Tradizione e cultura trobadorica nelle corti e nelle città venete», Storia della cultura veneta, Vicenza: Neri Pozza, l: 453-565 (ara a Gianfranco Folena, Cultura e lingue nel Veneto medievale, Pàdua: Programma, 1990, 1-137).

Gauchat, Louis \& Heinrich KeHRLI, 1891: «ll canzoniere provenzale $H$ (Cod. Vaticano 3207)», Studj di filologia romanza, 5, 341-568.

GONÇALVES, Elsa, 2000: «...soo maravilhado / eu d'En Sordel...», Cultura Neolatina, 60, 371-386.

GoUIRAN, Gérard, 1993: «À propos de l'esprit de Sordel», 'Et c'est la fin pour quoy sommes ensemble'. Hommage à Jean Dufournet, París: Champion, II, 645-659.

GouIRAN, Gérard, 2006: «'S'aisi son tuit freich cum el l'autre Lombart, non son bon ad amor' ou la mauvaise réputation de Sordel», Trobadors a la Península Ibèrica. Homenatge al Dr. Martí de Riquer, ed. V. Beltran, M. Simó i E. Roig, Barcelona: Publicacions de l'Abadia de Montserrat, 171-194.

GoUIRAN, Gérard, 2008: «Sur quelques troubadours qui franchirent les Alpes du temps de la croisade contre les Albigeois», I trovatori nel Veneto e a Venezia. Atti del Convegno Internazionale (Venezia, 2004), ed. G. Lachin, Roma-Pàdua: Antenore, 97-133.

GRLMA II/4, $1990=$ Grundriss der Romanischen Literaturen des Mittelalters, II: Les genres lyriques I Fasc. 4: B II: b. Descort und Lai, c. Sirventes, d. Sirventes-Kanzone, e. Cobla, f. Kreuzzugslied, g. Klagelied, Heidelberg: Universitätsverlag Winter.

Gröber, Gustav, 1877: «Die Liedersammlungen der Troubadours», Romanische Studien, 2, 337-670.
GUIDA, Saverio, 2006a: «Sulla tenzone tra Uget e Reculaire», Studi mediolatini e volgari, 52,181-216.

GuIDA, Saverio, 2006b: «Lo (pseudo) pseudonimo della danseta di Uc de Saint Circ (BdT 457,41: 3)», Tenso, 21, 1-15.

GuIDA, Saverio, 2008: «Esperienza trobadorica e realtà veneta», I trovatori nel Veneto e a Venezia. Atti del Convegno Internazionale (Venezia, 2004), ed. G. Lachin, Roma-Padova: Antenore, 135-170.

HPM = Historia Patriae Monumenta edita iussu regis Karoli Alberti, Torí: Fratelli Bocca, 22 voll. (Leges municipales: vol. II, 18z8; vol. XVI.1 \& vol. XVI.2, 1876).

HuILLARD-BréHolLes, Jean Louis Alphonse, 1852-1861: Historia diplomatica Federici Secundi, 6 vols, París: Plon.

LÉGLU, Catherine, 2002: «Vernacular poems and inquisitors in Languedoc and Champagne, c. 1242-1249»», Viator, 33, 117-132.

LeVY, Emil (ed.), 1880: Guilhem Figueira, ein provenzalischer Troubadour, Berlín: Liebrecht.

MANCINI, Mario, 1991: «Aimeric de Peguilhan rhétoriqueur e giullare», Il medioevo nella Marca. Trovatori, giullari, letterati a Treviso nei secoli XIII e XIV, Atti del Convegno, (Treviso, 1990), ed. M. L. Meneghetti i F. Zambon, Treviso: Premio Comisso, 45-89.

Meliga, Walter, 2003: «ll pubblico dei testi cortesi»», Lo spazio letterario del medioevo. 2. II medioevo volgare, dir. P. Boitani, M. Mancini i A. Varvaro, Roma: Salerno, III, 79-123.

Meneghetti, Maria Luisa, 1989: «ll florilegio trobadorico di Ferrarino da Ferrara», Miscellanea di studi in onore di Aurelio Roncaglia a cinquant'anni dalla sua laurea, Mòdena: Mucchi, III, 853-871.

Meneghetti, Maria Luisa, 1991: «Les florilèges dans la tradition lyrique des troubadours», Lyrique romane médiévale: la tradition des chansonniers. Actes du Colloque de Liège, 1989, ed. M. Tyssens, Liège: Faculté de philosophie et lettres de I'Université de Liège, 43-59.

Menichetti, Caterina, 2013: «Le tenzoni del canzoniere E: fonti, strategie compilative, coordinate storicoculturali della sezione», Studi mediolatini e volgari, 59, 173-224.

MGH 1866 = Monumenta Germaniae Historica, Scriptores XIX, ed. G. $H$. Pertz, Hannover: Impensis Bibliopolii Avlici Hahnian.

NegrI, Antonella, 2010: «Guillem Figueira Aimeric de Peguillan, Anc tan bel colp de joncada Anc tan bella espazada (BdT 217.1a, 10.9)», Lecturae tropatorum, 3, 1-23.

Negri, Antonella, 2012: Aimeric de Peguillan, Poesie, Roma: Carocci.

Noто, Giuseppe, 1998: II giullare e il trovatore nelle liriche e nelle "biografie" provenzali, Alessandria: Edizioni dell'Orso.

Noто, Giuseppe, 2003: 'Intavulare'. Tavole di canzonieri romanzi. I. Canzonieri provenzali. 4. Firenze, Biblioteca Medicea Laurenziana. P (Plut. 41. 42), Mòdena: Mucchi.

Noto, Giuseppe, 2006: «Florilegi di coblas e tendenze della letteratura in volgare italiano: osservazioni sulle raccolte e sulle seriazioni di poesie nell'Italia tra Duecento e Trecento», «Liber», «Fragmenta», «Libellus» prima e dopo Petrarca. In ricordo di d`Arco Silvio Avalle, ed. F. Lo Monaco, L. C. Rossi i N. Scaffai, Florència: Edizioni del Galluzzo, 93-105. 
Nото, Giuseppe, 2010: «Anonimo, Mout home son qe dizon q'an amicx (BdT 461.170) con Anonimi, Fraire, tot lo sen e.l saber (BdT 461.123b), Quecs deuria per aver esser pros (BdT 461.173), Mant home son ades plus cobetos (BdT 461.162)», Lecturae tropatorum, 3, 1-24.

OMONT, Charles, 1916: «La collection Doat à la Bibliothèque nationale. Documents sur les recherches de Doat dans les archives du sudouest de la France de 1663 à 1670». Bibliothèque de l'École des Chartes, 77, 286-336.

Perugl, Maurizio, 1988: «Sordello: una vita irrequieta», Atti e memorie della Real Accademia Virgiliana di Mantova, 56, 91-117.

Petrossi, Antonio, 2009: «Le coblas esparsas occitane anonime. Studio ed edizione dei testi», Tesi de doctorat, Università di Napoli Federico II.

POE, Elizabeth W., 200oa: «Cobleiarai, car mi platz: the role of the cobla in the Occitan tradition», Medieval lyric: genres in historical context, ed. W. Paden, Urbana i Chicago: University of Illinois Press, 68-94.
POE, Elizabeth W., 20oob: 'Compilatio'. Lyric texts and prose commentaries in troubadour manuscript $\mathrm{H}$ (Vat. Lat. 3207), Lexington (KY): French Forum Publishers.

RadAelli, Anna, 2000: «La danseta di Uc de Saint Circ (BdT 457,41)», Cultura Neolatina, 60, 59-88.

ResCon, Stefano, 2014: «La lirica trobadorica nella Toscana del Duecento. Canali e forme della diffusione», Carte Romanze, 2, 269-300.

RESCONI, Stefano, 2016: «Forme del rapporto interdiscorsivo tra raccolte di coblas provenzali e poesia comica toscana», Forme letterarie del Medioevo romanzo: testo, interpretazione e storia, Atti dell'XI Congresso triennale della Società Italiana di Filologia Romanza (Catania, 2015), ed. Antonio Pioletti i Stefano Rapisarda, Soveria Mannelli: Rubbettino, 419-437

RIEGER, Angelica, 1988: «La cobla esparsa anonyme. Phénoménologie d'un genre troubadouresque», Actes du XVIII Congrès International de Linguistique et de Philologie Romanes, Trèves (Trier) 1986,
Tübingen: Niemeyer, VI, 202-218.

RIQUeR, Martí de, 1972: «El trovador Huguet de Mataplana», Studia Hispanica in Honorem R. Lapesa, Madrid: Gredos, I, 455-494.

Rossl, Luciano, 2005: «Aspetti dell'invettiva nell'Occitania del XIII secolo: Aimeric de Peguilhan e i suoi sodali», Cecco Angiolieri e la poesia satirica medievale, ed. S. Carrai i G. Marrani, Florència: Edizioni del Galluzzo, 31-49.

SHePARD, William P. \& Frank M. Chambers (edd.), 1950: The poems of Aimeric de Peguilhan, Evanston (IL): Northwestern University Press.

TIRABOSCHI, Girolamo (ed.), 1790: Dell'origine della poesia rimata, opera di Giammaria Barbieri modenese, pubblicata e con annotazioni illustrata dal cav. ab. Gerolamo Tiraboschi, Mòdena: Società tipografica modenese.

UGoLINI, Francesco, 1939: La poesia provenzale e l'Italia, Mòdena: STEM. 


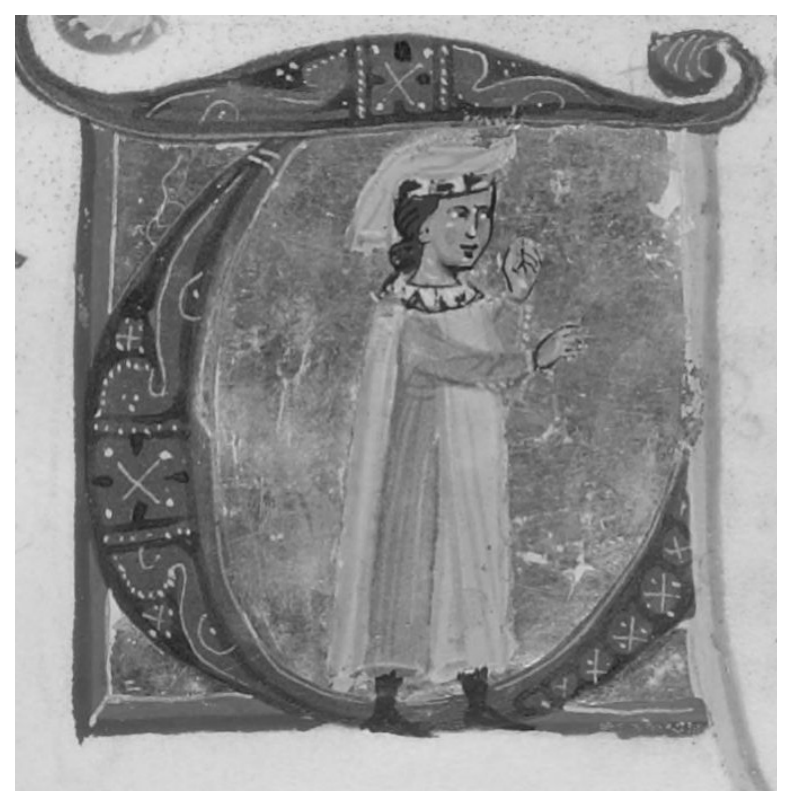

El trobador Sordello al cançoner I (París, BnF, 854, f. 123r). 